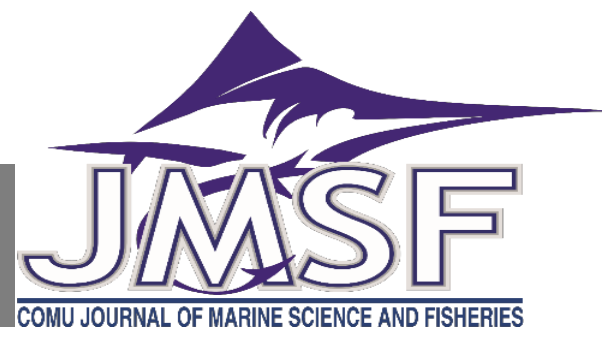

RESEARCH ARTICLE

\title{
Socio-economic Status of Small-Scale Fisheries, Çanakkale (Northern Aegean) Turkey
}

\author{
Erhan Şahin ${ }^{1}$, Uğur Özekinci2 ${ }^{*}$ \\ ${ }^{1}$ Çanakkale Onsekiz Mart Üniversitesi Fen Bilimleri Ens. Su Ürünleri Avlama ve İșleme Teknolojisi ABD. \\ 2 Çanakkale Onsekiz Mart Üniversitesi, Deniz Bilimleri ve Teknolojisi Fakültesi, Terzioğlu Kampusü 17100 Çanakkale, Türkiye. \\ Correspondent: uozekinci@comu.edu.tr \\ Received: $21.05 .2020 \quad$ Accepted: 12.06 .2020 \\ Erhan Şahin: Orcid 0000-0002-8085-0253, Uğur Özekinci: Orcid 0000-0003-2207-0168
}

How to cite this article: Şahin, E., \& Özekinci, U., (2020). Socio-economic status of small-scale fisheries, Çanakkale (Northern Aegean) Turkey. COMU J. Mar. Sci. Fish, 3(1): 19-26. DOI: 10.46384/jmsf.740894

\begin{abstract}
In this study, the socio-economic structure of the fishermen operating in Çanakkale were examined. Related data were obtained from regional fishery cooperatives and face-to-face interviews with boat owners that are registered in the Provincial Directorate of Agriculture and Forestry. For this purpose, 803 fishing vessels smaller than $12 \mathrm{~m}$ and licensed in Çanakkale were divided into 3 size groups and a survey was conducted with a total of $242(30.14 \%)$ fishermen selected by "stratified random sampling". Results indicated that $95.04 \%$ of the boats were made of wood, $97.11 \%$ of the boat owners were male, and all the fishermen were over 25 years old. The majority of fishermen (46.69\%), were primary school graduates. In addition, almost $90 \%$ of fishermen had social securities. When asked why they chose fishing as an occupation $35.54 \%$ stated that it was family profession and $32.23 \%$ emphasized that they had no other option while $29.75 \%$ expressed their passion for the sea. In addition, $63.63 \%$ of the fishermen never had a profession other than fisheries, $61.57 \%$ were members of fishing cooperatives and 90\% marketed their products through brokers. Although $66.70 \%$ of the fishermen stated that they were not satisfied with the level of income, the majority $(89.67 \%)$ did not want to leave fisheries. The results indicated that, despite small scale fisheries is a challenging occupation with limited income, it is perceived as an crucial and important way of life in Çanakkale region. The results of the study can assist policymakers to develop management strategies regarding the sustainability of small-scale fisheries in the province of Çanakkale.*This research is a part of Erhan Şahin's MSc Thesis.
\end{abstract}

Keywords: Çanakkale, Fisheries, Socio-Economy, North Aegean Sea

\section{Küçük Ölçekli Balıkçılığın Sosyo-Ekonomik Durumu, Çanakkale (Kuzey Ege), Türkiye}

Özet: Bu çalışmada, Çanakkale'de faaliyet gösteren küçük ölçekli balıkçıların sosyo-ekonomik durumu ortaya çıkarılmıştır. Çalışmada balıkçıları sosyo-ekonomik yönden değerlendire bilmek için gerekli veriler; bölgede faaliyet gösteren su ürünleri kooperatifleri, Tarım ve Orman İl Müdürlüğü kayıtlarda yer alan tekne sahipleri ile yapılan yüz yüze görüşmelerden elde edilmiştir. Bu amaçla Çanakkale'de ruhsatlı 12 m'den küçük toplam 803 adet balıkçı gemisi, 3 boy grubuna ayrılarak her boy grubunda "Tabakalı rastgele örnekleme" gerçekleştirilerek toplam 242 adet $(\% 30,14)$ balıkçılla anket yapılmıştır. Çalışmada teknelerin \%95,04 ‘ünün ahşap malzemeden yapıldığı, tekne sahiplerinin \%97,11'inin erkek olduğu, balıkçıların 25 yaşından büyük oldukları görülmüştür. Balıkçıların \%46,69’u gibi büyük çoğunluğunun ilkokul mezunu olduğu belirlenmiştir. Bunun yanında, balıkçıların \%90'nına yakını sosyal güvenceye sahiptir. Ayrıca balıkçılığı seçme nedenlerinin ne olduğu sorusuna \%35,54’ü baba mesleği, \%32,23'ü zorunluluk, \%29,75'i sevmek cevabını vermişlerdir. Ankete katılan balıkçıların \%63,63'ünün balıkçılık dışında bir mesleğinin olmadığ 1 , \%61,57'sinin bir kooperatife ortak olduğu ve ürünlerini komisyoncu (\%90) aracılığıyla pazarladıkları belirlenmiştir. Elde edilen gelirden \%66,70'i memnun olmasa da çoğunluğu $(\% 89,67)$ balıkçılığı bırakmak istememektedir. Sonuç olarak Küçük Ölçekli Balıkçılık yapılması zor ve zahmetli aynı zamanda gelir açısından yetersiz olsa da Çanakkale bölgesi için vazgeçilmez bir meslek ve geçim kaynağıdır. Çalışmanın sonuçları, balıkçılık yönetimindeki politika yapıcıların Çanakkale ilindeki küçük ölçekli balıkçılık mesleğinin sürdürülebilirliğine ilişkin politikalar geliştirmelerine yardımcı olabilir. Bu araştırma, Erhan ŞAHİN'nin Yüksek Lisans Tez çalışmasının bir bölümüdür.

Anahtar Kelimeler: Çanakkale, Balıkçılık, Sosyo-Ekonomi, Kuzey Ege Denizi 


\section{Giriş}

Çanakkale, Türkiye'nin Marmara Denizi, Çanakkale Boğazı ve Ege Denizi olmak üzere 671 km uzunluğunda, Asya ve Avrupa kitalarında, denize kıyısı olan iki ilinden biri konumundadır. Bu özelliği ile denizler arasında gerçekleşen balık göçleri nedeniyle, ticari ve sportif amaçlı balıkçılık faaliyetlerinin yoğunluğunu arttırmakta ve bölgenin balıkçılıkta önemli bir merkez olmasını sağlamaktadır (Özekinci ve diğ. 2006; Akyol ve Ceyhan, 2010). Türkiye denizlerinde su ürünleri avcılık faaliyetinde bulunan tekne sayısı 15352 adet olarak rapor edilmiş olup, bunların 13783 adeti $(\% 89,8) 12$ m'den küçük, 1569 adeti $(\% 10,2)$ ise 12 m üzeri teknelerden oluşmaktadır (TUIK, 2019). Çanakkale İl Tarım ve Orman Müdürlüğü 2019 yılı verilerine göre Çanakkale'de ruhsatlı 827 adet balıkçı teknesi bulunmaktadır. Çanakkale ili balıkçılığı konusunda Özekinci ve diğ. (2006) tarafindan yapılan çalışmada, 2006 yılında bölgesinde 1065 adet ruhsatlı tekne bulunduğunu ve bunların \%3,2'sinin Girgır ve Trol teknelerinden geri kalan \%96,8'inin ise diğer tekneler sınıfında yer alan küçük balıkçı tekneleri olduğundan bahsetmiştir. 2019 yılı verilerine göre ise balıkçı teknelerinin 803 adeti $(\% 97,09) 12$ m'den küçük balıkçı tekneleri oluşturmaktadır (TOB, SUBİS,2019). "Küçük Ölçekli Balıkçılık (KÖB)" faaliyeti gerçekleştiren balıkçılar olarak tanımlanan bu teknelerle, kıyı alanı av sahası kabul edilmekte, uzatma ağları, paragat, kaldırma ağları, olta, tuzaklar gibi avlanma araçlarını kullanmak sureti ile günü birlik ticari avcılık yapılmaktadır (Ünal, 2001). KÖB faaliyetinin ticari faaliyetler yanında, hobi amaçlı balıkçılık yapanları da bu grup içine aldığ bilinmektedir (Hoşsucu, ve diğ., 1997). Bununla birlikte, Ünal ve Ulman (2020), KÖB için mevcut su ürünleri kanununda bir tanım olmadığını belirterek, KÖB'ları pasif av takımı kullanan (uzatma ağları, olta takımları, tuzaklar vb. gibi) ve yakalamalarını ticari olarak satan ve 12 m'den küçük tekneler kullanan balıkçılar olarak tanımladıkları rapor edilmektedir.

Balıkçılık yönetimi açısından KÖB faaliyetlerinin düzenlenmesi ve yönetiminin sağlanabilmesinde balık popülasyonlarına ait veriler kadar, balıkçılık faaliyetlerine ait sosyo- ekonomik verilerin de gerekliliği üzerinde durulmaktadır (Franquesa, Malouli ve Alarcon, 2001; Sabatella ve Franquesa, 2004). Nitekim FAO balıkçılığın ekonomik olarak sürdürülebilirliği ve uygulanabilirliği ile ilgili klavuzlar yayınlamıştır (Lery ve diğ 1999). Bununla birlikte, Türkiye'nin farklı denizlerinde balıkçıların sosyo-ekonomik yönden analizleri ile ilgili birçok çalışma yapılmıştır (Ünal 2001, 2003, 2004; Yücel 2006; Doğan ve Gönülal 2011; Yağlığlu 2013; Çalık ve Sağlam 2015; Alıçlı, Doğan ve Altunay, 2019; Ayyıldız ve Balık, 2019). Ancak, bu çalışma sonuçları yerel veya merkezi yönetim merkezleri tarafından ne yazık ki fazla dikkate alınmamıştır. Ünal ve Franquesa (2010), balıkçılık ekonomisi konusundaki çalışmaların birçok ülkede yaygın olarak kullanılmasına rağmen, Türkiye'de nadir olarak değerlendirildiğinden bahsetmiştir. Özellikle Akdeniz Genel Balıkçılık Komisyonu-Ekonomik ve Sosyal Bilimler Alt Komitesi (GFCM-SCESS), sosyo-ekonomik yönden verilerin değerlendirildiği toplantılar düzenlemektedir. $\mathrm{Bu}$ toplantı sonuçları, balıkçılık yönetim politikalarının geliştirilmesinde sosyo-ekonomik verilerin göz ardı edilemeyeceğini göstermektedir (FAO, 2020). Balıkçılardan elde edilecek sosyo-ekonomik veriler, balıçcılık kaynakları ve balıkçılık faaliyetleri arasında ilişki kurularak gelecekteki durum hakkında gerekli düzenlemeler için kullanılabilecek net tahminler yapılmasına olanak sağlanmış olacaktır (Tzanatos vd diğ., 2006; Salas ve diğ. 2007; Korkmaz ve Coşkun 2016; Ünal ve Ulman 2020).

$\mathrm{Bu}$ çalışmada, Çanakkale ili sınırlarında faaliyet gösteren Küçük Ölçekli Balıkçıların sosyo-ekonomik yönden incelenerek, gelecekte yönetimsel olarak planlanacak düzenlemeler ve stratejilere veri kaynağ1 sağlanması amaçlanmıştır.

\section{Materyal ve Yöntem}

Bu çalışma, 2018-2019 av sezonunda, Çanakkale ili sınırları içinde faaliyet göstermekte olan, Tarım ve Orman İl Müdürlüğü tarafından "Balıkçı Gemileri İçin Su Ürünleri Ruhsat Tezkeresi” verilmiş bulunan, balıkçılık kooperatifleri ve üst birliklerine kayıtlı 12 m'ye kadar olan balıkçı teknesi sahipleri ile yapılan görüşmelerle saha çalışmaları gerçekleştirilmiştir. Bu çalışmada balıkçı gemisi tam boyu 12 metreden büyük olanlar, çalışmanın dişında tutulmuştur.

Çalışma balıkçılarla yüz yüze görüşmelerle (anketler) yapılmıştır. Balıkçılara ait örneklemeler olasılıklı örnekleme yöntemlerinden "Tabakalı örnekleme" esasına göre oluşturulmuştur (Yazıcıŏlu ve Erdoğan, 2004). Bu amaçla balıkçıların sahip olduğu tekne boyu göz önün de bulundurulmuştur. Tekneler, yıl içinde, tek av aracı (örneğin; olta takımları), iki av aracı (örneğin; olta + uzatma ağı), ve 3 av aracı (örneğin; uzatma ağ $1+$ olta + paragat) kullanılanlar dikkate alınarak, 3 boy grubuna ayrılmış, her boy grubunda rastgele örnekleme gerçekleştirilmiş ve toplam 242 adet $(\% 30,14)$ balıkçıyla anket yapılmıştır (Tablo 1).

$\mathrm{Bu}$ balıkçılar ile yapılan görüşmelerden elde edilen veriler Microsoft Excel programına aktarılmış ve analizleri gerçekleştirilmiştir. Analizlerde, balıkçıların, aile durumları, eğitim düzeyleri, araba ve ev mülkiyeti, balıkçılığ 1 seçme nedenleri, sosyal aktiviteleri, sosyal güvenceleri, su ürünleri kooperatifine ortaklık durumları, kullandıkları av araçları, av operasyon süreleri, av döneminde kazanılan ücret-miktarı gibi sorular yöneltilerek alınan cevaplar doğrultusunda verilerin değerlendirilmesi ve incelenmesi yapılmıştır. 
Tablo 1. Çalışmada KÖB tekne boy grupları ve Ankete Katılan Tekne sayısı ve \% oranları

\begin{tabular}{|c|c|c|c|c|c|}
\hline & Tekne Boyu & $\begin{array}{c}\text { KÖB yapan } \\
\text { Toplam Tekne sayısı } \\
\mathbf{A} \text { (adet) }\end{array}$ & $\begin{array}{c}\% \\
(\mathrm{~A})\end{array}$ & $\begin{array}{l}\text { Ankete katılan } \\
\text { KÖB Tekne Sayısı } \\
\text { B (adet) }\end{array}$ & $\begin{array}{c}\% \\
(\mathrm{~B} / \mathrm{A})\end{array}$ \\
\hline 1. Grup & $0-6,99 \mathrm{~m}$ & 264 & 32,88 & 91 & 34,47 \\
\hline 2.Grup & 7- 9,99 m & 469 & 58,41 & 135 & 28,78 \\
\hline \multirow[t]{2}{*}{ 3. Grup } & $10-11,99 \mathrm{~m}$ & 70 & 8,72 & 16 & 22,86 \\
\hline & Toplam & 803 & 100,00 & 242 & 30,14 \\
\hline
\end{tabular}

$\mathrm{Bu}$ balıkçılar ile yapılan görüşmelerden elde edilen veriler Microsoft Excel programına aktarılmış ve analizleri gerçekleştirilmiştir. Analizlerde, balıkçıların, aile durumları, eğitim düzeyleri, araba ve ev mülkiyeti, balıkçılığı seçme nedenleri, sosyal aktiviteleri, sosyal güvenceleri, su ürünleri kooperatifine ortaklık durumları, kullandıkları av araçları, av operasyon süreleri, av döneminde kazanılan ücret-miktarı gibi sorular yöneltilerek alınan cevaplar doğrultusunda verilerin değerlendirilmesi ve incelenmesi yapılmıştır.

\section{Bulgular ve Tartışma}

Çalışmanın yapıldığı, Çanakkale ili kıyılarında KÖB faaliyetinde bulunan toplam 827 teknenin 803 adeti 12 m'den küçük balıkçı tekneleri oluşturduğu ve teknelerin \%95,04 'ünün ahşap, \% 4,96'sının fiber malzemeden oluşmakta olduğu, saç teknenin bulunmadığı belirlenmiştir. Ahşap teknelerin tercih edilmesinin nedeni olarak bakım ve onarımlarının diğer teknelere göre ucuz ve kolay olmasıdır. Ayyıldız ve Balık (2019) Yalova ilinde yaptıkları çalışmada tekne materyalinin benzer sebeplerle daha fazla tercih edildiğini belirtmişlerdir.

Çalışmada KÖB balıkçılık faaliyeti gerçekleştiren ve ankete katılan balıkçılarını demografik özelliklerine bakıldığında (Tablo 2) tekne sahibi olan balıkçıların \%2,89'u kadın \%97,11'i erkek bireylerden oluşmaktadır.

Balıkçılık mesleği genel olarak erkek mesleği olarak kabul edilse de kadınlar da bu meslekte yer almaktadır. Nitekim, Göncüoğlu ve Ünal (2011) kadın balıkçılar üzerine yaptığı çalışmada Güney Ege'de Muğla ilinde tekne sahibi olan kadın balıkçıların \% 4,2 oranına sahip olduğunu belirtmiş ve kadınların da bu mesleğin içinde yer aldığından bahsetmiştir. Ayyıldız ve Balık (2019) ise Yalova ilinde kadın balıkçının olmadığını, bunun nedenini kadınların balıkçılığa ilgi duymaması ya da balıkçıların sosyo- kültürel yapıdan kaynaklı eşlerini çalıştırmak istememeleri olarak belirtmiştir.
Tablo 2. Balıkçıların demografik özellikleri

\begin{tabular}{|c|c|c|}
\hline Balıkçıların Demografik Özellikleri & Adet & Yüzde (\%) \\
\hline \multicolumn{3}{|l|}{ Cinsiyet } \\
\hline Kadın & 7 & 2,89 \\
\hline Erkek & 235 & 97,11 \\
\hline \multicolumn{3}{|l|}{ Yaş Grupları } \\
\hline $16-25$ yaş & - & - \\
\hline $25-44$ yaş & 61 & 25,21 \\
\hline $45-59$ yaş & 124 & 51,24 \\
\hline $60>$ yaş & 57 & 23,55 \\
\hline \multicolumn{3}{|l|}{ Öğrenim Durumu } \\
\hline Okur-Yazar & 3 & 1,24 \\
\hline İlkokul & 113 & 46,69 \\
\hline Ortaokul & 50 & 20,66 \\
\hline Lise ve Dengi & 51 & 21,07 \\
\hline Üniversite & 25 & 10,33 \\
\hline \multicolumn{3}{|l|}{ Medeni Hali } \\
\hline Evli & 204 & 84,30 \\
\hline Bekar & 38 & 15,70 \\
\hline \multicolumn{3}{|l|}{ Çocuk Sayısı } \\
\hline 0 Çocuk & 12 & 5,88 \\
\hline 1 Çocuk & 44 & 21,57 \\
\hline 2 Çocuk & 116 & 56,86 \\
\hline 3 Çocuk & 30 & 14,71 \\
\hline 4 Çocuk & 2 & 0,98 \\
\hline
\end{tabular}

Çalışmaya katılan balıkçıların yaş dağılımında, 45-59 yaş grubunun \%51,24 ile en fazla orana sahip olduğu, 60 yaşından büyük olanların oranının ise $\% 23,55^{\prime}$ lik oranla en az balıkçıdan oluştuğu belirlenmiştir (Tablo 2). 16-25 yaşlarında balıkçıya rastlanılmamış olması oldukça önemlidir. Göncüoğlu-Bodur ve diğ. (2017), İzmir Körfezinde kalamar avcıları ile yaptıkları çalışmada \%39 ile en yüksek yaş oranın 56-65 yaş aralığında olduğundan bahsetmiştir. KÖB yapan gemi sahiplerinin yaş ortalaması ile ilgili bilgilerin yer aldığ 1 çalışmalar da, Akdeniz'de 32-76 yaş aralığı (Karadal, 2014), Marmara Denizi, Tekirdağ ilinde 45-60 yaş (Şahin, 
2006; Alıçlı ve diğ. 2019), Karadeniz de 40 yaş ve üzeri (Uzmanoğlu ve Soylu 2006; Özbek 2014; Çalık ve Sağlam 2015; Sağlam ve Çalık 2016) olduğundan bahsedilmektedir. Tüm bu çalışmalar gençlerin çalışma şartlarının ağır olması nedeniyle balıkçılığa olan ilgilerinin az olduğu sonucunu çıkarmaktadır.

Türkiye kıyılarında balıkçıların eğitim durumları ile ilgili yapılan çalışmaların birçoğunda balıkçıların \%50'si ve daha fazlasının ilkokul mezunu oldukları belirtilmektedir (Özyurt, 2013; Karadal, 2014; Demirci, Aytekin ve Şimşek, 2015; Alıçlı ve diğ. 2019). Bu çalışmada da balıkçıların eğitim durumları ile ilgili elde edilen bilgilere göre \%46,69'u gibi büyük çoğunluğunun ilkokul öğrenimine sahip olduğu belirlenmiştir (Tablo 2). Kuzey Ege Gökçeada balıkçılığ1 konusunda Doğan ve Gönülal (2011)'da gerçekleştirilen çalışmada da benzer olarak balıkçıların \%54,2'sinin ilkokul mezunudur. Balıkçıların eğitim düzeyi ile farklı sonuçların alındığı çalışmalarda mevcuttur, örneğin; Ordu ilinde Çalık ve Sağlam (2015) ve Yalova ilinde Ayyıldız ve Balık (2019) tarafından yapılan çalışmalarda lise mezunlarının oranını sırasıyla $\% 55,10$ ve $\% 75$ olarak bildirmişlerdir. Tüm bu sonuçlar balıkçıların çoğunluğunun an az temel eğitim düzeyinde bir okul tamamladığı ve okul yazar olmayanların bulunmadığı konusunda benzer sonuçlar göstermiştir. Üniversite mezunu balıkçı oranının diğer çalışmalarda \%1-2 gibi çok düşük bir oranda bildirilmesine karşın, mevcut çalışmada \%10,33 gibi bir orana sahiptir. Bu farkın, baba mesleği balıkçılık olanların ve bölgede kamu sektöründe çalışıp balıkçılığı ek iş olarak yapanların sayısının fazlalığından kaynaklandığı düşünülmektedir.

Balıkçıların \%84,30'u evli ve bunların \%56,86'sının 2 çocuk sahibi olduğu belirlenmiştir (Tablo 2). Balıkçıların medeni durumu ve çocuk sayısı bakımında tüm kıyılarımızda yapılan çalışmalarda benzer sonuçlar elde edildiği ve balıkçıların çoğunluğuna yakınının evli ve en az 2 çocuk sahibi olduğu görülmüştür (Doğan 2010; Özyurt, 2013; Karadal, 2014; Demirci ve diğ. 2015; Alıçlı ve diğ. 2019).

Araştırmada, balıkçıların sosyo-ekonomik özelliklerinin belirlenmesi amacıyla yöneltilen yedi soruya ait bilgiler Tablo 3 'te verilmiştir. Balıkçıların sosyal güvenlik durumlarının belirlenmesi amaciyla yöneltilen soru ile \%42,56'sının SGK, \%25,21'inin BAĞ-KUR, \%17,77'sinin Emekli sandığından faydalandıkları saptanmıştır. Sosyal güvencesi olmayan balıkçıların oranı ise \%9,09 olduğu belirlenmiştir. Çeliker ve diğ. (2006) ve Çeliker ve diğ. (2008) yaptıkları çalışmada sırasıyla, KÖB faaliyeti gösteren Karadeniz balıkçılarının $\% 72,08$ 'sinin, Ege Deniz'inde ise \%57,47'sinin sosyal güvenceye sahip olduğundan bahsedilmektedir. Ünal ve Franquesa (2010), orta ve güney Ege Deniz'inde yapığı çalışmada sosyal yardım alan balıkçıların en fazla oranda
Karaburun'da (\%93) olduğunu, Ünal ve diğ. (2015), Datça-Bozburun'da yaptıkları çalışmada da bu oranın $\% 87$ olduğundan bahsetmişlerdir. Türkiye genelinde de KÖB faaliyeti gösteren balıkçılarının sosyal güvenceye sahip olarak çalıştıkları görülmektedir (Çeliker ve diğ. 2006; Çeliker ve diğ. 2008; Özyurt, 2013; Çalık ve Sağlam 2015; Alıçlı ve diğ. 2019).

Balıkçıların ev ve otomobil mülkiyetinin bulunup bulunmadığının belirlenmesi amacıyla yöneltilen soruya verdikleri cevaplara göre, balıkçıların \% 78,93'ünün kendi evinde oturduğu, \%55,79'unun otomobili bulunduğu tespit edilmiştir (Tablo 3). Akdeniz'de yapılan çalışmada balıkçıların \%61'inin (Karadal, 2014), Karadeniz'de ise \%80,95'i kendi evinde oturduğu ifade edilmiştir (Özyurt, 2013). Balıkçıların bazılarının kazancın genelde yetersiz olması nedeniyle ev veya otomobil mülkiyetinde sadece balıkçılık gelirini kullanamadıklarını, aileden geldiği ya da aileden yardım aldıklarını belirtmişlerdir.

Tablo 3. Balıkçıların sosyo-ekonomik durumları

\begin{tabular}{|c|c|c|}
\hline Balıkçıların Sosyo-Ekonomik yapıları & Adet & Yüzde (\%) \\
\hline \multicolumn{3}{|l|}{ Sosyal Güvenlik Durumu } \\
\hline SGK & 103 & 42,56 \\
\hline BAĞ-KUR & 61 & 25,21 \\
\hline Emekli Sandığı & 43 & 17,77 \\
\hline Yeşil Kart & 3 & 1,24 \\
\hline Yok & 22 & 9,09 \\
\hline Diğer & 3 & 1,24 \\
\hline \multicolumn{3}{|l|}{ Ev Mülkiyeti } \\
\hline Kira & 45 & 18,60 \\
\hline Kendi Evi & 191 & 78,93 \\
\hline Diğer & 6 & 2,48 \\
\hline \multicolumn{3}{|l|}{ Otomobil Mülkiyeti } \\
\hline Var & 135 & 55,79 \\
\hline Yok & 102 & 42,15 \\
\hline Diğer & 5 & 2,07 \\
\hline \multicolumn{3}{|l|}{ Balıkçılığı Seçme Nedeni } \\
\hline Baba Mesleği & 86 & 35,54 \\
\hline Zorunluluk & 78 & 32,23 \\
\hline Sevmek & 72 & 29,75 \\
\hline Diğer & 6 & 2,48 \\
\hline \multicolumn{3}{|l|}{ Balıkçılık Dıșındaki Meslekleri } \\
\hline Yok & 154 & 63,63 \\
\hline Çiftçi & 19 & 7,85 \\
\hline Kamu Personeli & 18 & 7,44 \\
\hline Özel Sektör & 24 & 9,92 \\
\hline Diğer & 27 & 11,16 \\
\hline \multicolumn{3}{|l|}{ Balıkçıların Sosyal Aktiviteleri } \\
\hline Sinema & 11 & 4,55 \\
\hline Tiyatro & 21 & 8,68 \\
\hline Gezi & 53 & 21,90 \\
\hline Spor & 13 & 5,37 \\
\hline Diğer & 58 & 23,97 \\
\hline Boş & 86 & 35,54 \\
\hline \multicolumn{3}{|l|}{ Kooperatif Ortaklığı } \\
\hline Evet & 149 & 61,57 \\
\hline Hayır & 93 & 38,43 \\
\hline
\end{tabular}

Balıkçılığı seçme nedenlerinin ne olduğu sorusuna \%35,54'ü baba mesleği, \%32,23'ü zorunluluk, \%29,75'i sevmek cevabını vermişlerdir (Tablo3). Bu mesleğin seçilmesi ile ilgili önceki çalışmalarda verilen cevaplara bakıldığında da "Baba mesleği" olduğu için seçtiklerini belirtenler ilk sırada yer almışlardır (Özyurt, 2013; Çalık ve Sağlam 2015; Alıçlı ve diğ. 2019). Ayrıca, ilk sırada "Zorunluluk" cevabını verenlerin olduğu çalışmalar da bulunmaktadır (Doğan 2010; Karadal, 2014; Ayyıldız 
ve Balık 2019). Zorunlulukta en büyük etkenler, bölge de tarım arazisinin ve herhangi bir sanayileşmenin azlığ 1 veya deniz kenarında oturmak gibi nedenler etkili olmaktadır. Nitekim, Doğan ve Gönülal (2011) Gökçeada yaptıkları çalışmada mesleği yapma nedenini \%45,8 oranla "Deniz kenarında ikamet" olarak belirtmişlerdir.

Çalışmada ankete katılan balıkçıların \%63,63' ünün balıkçılık dışında bir mesleğinin olmadığı belirlenmiştir. Balıkçıların toplamda \%36,37'si ise balıkçılık dışında da bir mesleğe sahiptir. Bunların $\% 7,85$ 'i çiftçi, \%7,44'ü kamu personeli, \%9,92'si özel sektör, \%11,16'sı diğer meslek gruplarında da faaliyette bulunmaktadır (Tablo 3). Türkiye kıyılarında balıkçılık dışında mesleğe sahip olma oranı Karadeniz'de \%28 (Çalık ve Sağlam, 2015) olurken, Marmara da \%30 (Benli, 2009; Zengin ve Güngör 2017), Gökçeada da \%46 (Doğan ve Gönülal, 2011), Tekirdağ ilinde \%39,4 (Güngör ve diğ. 2007) olarak belirtilmiştir. Bunun yanında Ege Deniz'i İzmir Körfezi'nde olta ile kalamar avcılarının \%32'sinin (Göncüoğlu-Bodur ve diğ. 2017), DatçaBozburun Özel Çevre Koruma Bölgesi (SEPA) balıkçılarının \%41'inin asıl mesleğinin balıkçı olduğunu belirten çalışmalar da bulunmaktadır (Ünal ve diğ. 2015).

Balıkçıların sosyal aktivite durumları incelendiğinde \%4,55'i sinema, \%8,68'i tiyatro, \%21,90'1 gezi, \%23,97'si diğer seçeneğini işaretlemişlerdir. (Tablo 3). Balıkçıların \%35,54'ü, çalışma şartlarının ağır ve zaman alıcı olduğundan ve bu nedenle de diğer aktivitelere zaman ayıramadıklarından yakınarak bu soruyu boş bırakmıştır. Karadeniz'de yapılan çalışmada \%69,05'inin sosyal aktivite yapmadığı belirlenmiştir (Özyurt, 2013).

Balıkçıların kooperatifleşme veya dernek üyeliği gibi örgütlenme düzeylerinin belirlenmesi amacıyla yöneltilen anket sorusuna verdikleri cevapların değerlendirilmesi sonucunda \%61,57'sinin bir kooperatife ortak olduğu tespit edilmiştir. Akyol ve Perçin (2006) Tekirdağ ilinde, Çeliker ve diğ. (2008) Ege Bölgesi'nde gerçekleştirdikleri çalışmada \%52 ve $\% 56,7$ gibi düşük bir oranın olduğunu belirtmişlerdir. Ünal ve diğ. (2009) Ege kıyılarında 57 adet su ürünleri kooperatifi hakkında bilgiler vermiş ve kooperatife üye olma oranını $\% 76$ olarak belirtmiştir. Bunun yanında, Akdeniz ve Karadeniz'de yapılan çalışmalarda kooperatif veya derneğe üye olma oranının yaklaşık olarak \%70 olduğundan bahsedilmiştir (Karadal, 2014; Özyurt, 2013 Çeliker ve diğ. 2006).

Çalışmada, balıkçıların mesleki deneyim süreleri, personel durumu, ürün pazarlaması ve gelir memnuniyeti bilgilerine ilişkin veriler (Tablo 4) te gösterilmiştir. Balıkçılık tecrübe durumları incelendiğinde 21-30 yıl (\%29,75) balıkçılık yapmış olanların ilk sirada olduğu ve onu 11-20 yıl $(\% 26,03)$,
$31-40$ y1l $(\% 23,14)$ ve 40 y1lın $(\% 15,29)$ üzerinde balıkçılık yaptığı belirlenmiştir. Balıkçıların \%5,79'u (0-10 yıl) balıkçılığa emeklilikten sonra başlamış yada tayfa olarak çalışanlar oluşturmuştur (Tablo 4). Bizim çalışmamıza benzer sonuçlara sahip olarak, Gökçeada balıkçılığında mesleki tecrübenin 11-20 yıl $(\% 38,4)$, Ege denizi balıkçılığında ortala tecrübenin 24,79 yıl olduğu (Çeliker ve diğ. 2008), Karadeniz'de ise 25,05 yıl olduğu (Çeliker ve diğ. 2006) belirtilmiştir. 30 yıl ve üzeri tecrübeye sahip Akdeniz ve Karadeniz'de yapılan çalışmalarda (Özyurt, 2013; Karadal, 2014) tespit edilmiş çalışmalar olmakla birlikte bu balıkçıların daha çok 10m den büyük tekne sahipleri oluğu görülmektedir.

Balıkçıların günlük denizde kalma sürelerinin belirlenmesi amacıyla yöneltilen soruya, balıkçıların \%50'si 4-7 saat arasında cevabını vermiştir (Tablo 4). Bunun dışında \%40,91'i 8-11 saat arasında zaman geçirdiğini belirtmiştir. Avcılık süresi olarak 11 saatin $(\% 3,31)$ üzerinde faaliyet yürütenlerin olta ve uzatma ağı gibi en az iki av aracını kullananlar oluşturmaktadır.

Çanakkale bölgesinde faaliyet gösteren balıkçıların en çok kullandıkları av aracı olarak $\% 47,11$ 'inin el oltası, \%45,87'sinin uzatma ağı, $\% 5,37$ 'sinin paragat ve \%1,65'inin algarna kullandığ tespit edilmiştir (Tablo4). Özekinci ve diğ. (2006) bölgede faaliyet gösteren teknelerin \%67'sinin $7 \mathrm{~m}$ den küçük ve olta balıkçılığında kullanıldığından bahsetmiştir. Özellikle Çanakkale boğazında Karadeniz ve Ege denizi arasında gözlenen lüfer ve palamut göçü sırasında diğer avcılık faaliyeti gösteren balıkçıların birçoğunun olta balıkçılığına geçtiği bilinmektedir.

Çalışmada teknede çalışan personelin \%73,69'u aile fertlerinden, $\% 26,31$ 'i ise ücretli/paylı çalışan tayfadan oluşmaktadır. Yapılan görüşmelerden “Gerçek Kişiler İçin Ruhsat Tezkeresi” almak zorunluluğu olması nedeniyle balıkçıların bir kısmının eşlerini ve çocuklarını denize çıkarabilmek için çalışan olarak bildirdikleri saptanmıştır. Bölgede 10 m'nin altında tekne sayısının çok oluşu, fazla tayfa gerektirmeyen olta balıkçılığının yaygın olması ve tayfaya pay veya ücret ödeme isteğinin bulunmayışı aile fertlerinin avcılığa katılımını arttırmaktadır. Özyurt (2013), Karadeniz'de yaptığı çalışmada \%38,66'sının aile bireylerinin birlikte çalıştıklarını belirterek benzer gerekçeler göstermişlerdir.

Balıkçların \%90,50’sinin avladıkları ürünlerin pazarlamasını komisyoncu aracılığıyla gerçekleştirdiği saptanmıştır (Tablo 4). Türkiye'nin hemen hemen tüm kıyılarında; örneğin, Gökçeada da \%71 (Doğan ve Gönülal, 2011), Akdeniz'de \%79 (Karadal, 2014), İskenderun da \%87 (Demirci ve diğ. 2015), Bat1 Karadeniz de (Akçakoca) \%93 (Yağlıoğlu, 2013) oranları ile büyük çoğunluğunun komisyoncular aracılığı ile balıklarını pazara gönderdikleri görülmektedir. Çanakkale ilinde 
ürünün satışında ikinci sırada parakende satış $(\% 7,85)$ gelmektedir. Güngör ve diğ . (2007) Marmara denizi Tekirdağ ilinde yaptıkları çalışmada avcılı̆̆ı yapılan balığın komisyoncu haricinde ikinci olarak konserve fabrikalarına (\%23) verildiğini belirtmiştir.

Tablo 4. Balıkçılık süreleri, personel durumu, ürün pazarlaması ve gelir memnuniyeti bilgileri

\begin{tabular}{|c|c|c|}
\hline Balıkçılık Tecrübe Bilgileri & Adet & Yüzde(\%) \\
\hline \multicolumn{3}{|l|}{ Mesleki deneyim Süresi } \\
\hline $0-10 \mathrm{Y}_{11}$ & 14 & 5,79 \\
\hline 11.-20 Y1l & 63 & 26,03 \\
\hline $21-30 Y_{1} 1$ & 72 & 29,75 \\
\hline $31-40$ Y1l & 56 & 23,14 \\
\hline $40>Y_{11}$ & 37 & 15,29 \\
\hline \multicolumn{3}{|l|}{ Günlük Avcıllk Süresi } \\
\hline $0-3$ saat & 14 & 5,79 \\
\hline 4-7 saat & 121 & 50,00 \\
\hline $8-11$ saat & 99 & 40,91 \\
\hline $11>$ saat & 8 & 3,31 \\
\hline \multicolumn{3}{|l|}{ Kullanılan Av Araçları } \\
\hline El Oltasi & 114 & 47,11 \\
\hline Uzatma Ağ1 & 111 & 45,87 \\
\hline Paragat & 13 & 5,37 \\
\hline Algarna & 4 & 1,65 \\
\hline \multicolumn{3}{|l|}{ Çalışan Personel } \\
\hline Kendisi ve Aile Fertleri & 178 & 73,69 \\
\hline Ücretli/Paylı Çalışan Tayfa & 64 & 26,31 \\
\hline \multicolumn{3}{|c|}{ Avlanan Ürünlerin Pazarlanması } \\
\hline Komisyoncu & 219 & 90,50 \\
\hline Perakende & 19 & 7,85 \\
\hline Kendi & 3 & 1,24 \\
\hline Diğer & 1 & 0,41 \\
\hline \multicolumn{3}{|l|}{ Gelir Memnuniyeti } \\
\hline Evet & 83 & 34,30 \\
\hline Hayır & 159 & 65,70 \\
\hline \multicolumn{3}{|l|}{ Mesleği Bırakma isteği } \\
\hline Evet & 25 & 10,33 \\
\hline Hayır & 217 & 89,67 \\
\hline
\end{tabular}

Balıkçılıktan elde edilen kazanç konusunda "Gelir memnuniyet" durumunun belirlenmesi amaciyla yöneltilen soruya balıç̧ıların \%34,30'unun 'Evet' yanıtı verdiği, \%66,70'inin 'Hayır' yanıtı verdiği görülmektedir. Her ne kadar gelirinden memnun olmayanların oranı yüksek olsa da balıkçıların \%89,67'si balıkçılığı bırakmak istemediklerini belirtmişlerdir (Tablo 4). Ünal ve Franquesa (2010) balıkçılık mesleğini bırakmak isteyenlerin oranını \%25 olarak belirtirken, Ünal ve Ulman (2020) Karadeniz'de balıkçıların yarıdan fazlasının mesleği terk etme isteğinde olduğunu, Ege ve Akdeniz'de ise bu oranın \%25-40 aralığında değişim gösterdiğini belirtilmiştir.

\section{Sonuç}

Çanakkale bölgesi önemli bir balıkçılık sahası olma özelliğine sahiptir. Özellikle KÖB geçmişten günümüze ata mesleği olması yanında zorunluluktan dolayı da yapılıyor olması, bu kadim mesleğin kültürel olarak kuşaktan kuşağa aktarıldığını göstermektedir. Ayrıca, deniz kıyısında ikamet eden bölge halkının, kimisinin meslek ve kimisinin de ek iş imkanı gördüğü balıkçılık faaliyetine katılmaları sosyo-ekonomik açıdan önemlidir.

Sosyal ve ekonomik anlamda geleneksel olarak faaliyetlerini yürütmekte olan bu balıkçıların sektörde önemli bir yeri vardır ve varlığını devam ettirmesi büyük önem taşımaktadır. Ünal (2003) yılında yapmış olduğu çalışmada balıkçıların \%60'şının negatif ekonomik performansla çalışmasına rağmen balıkçılığa katılımın engellenemediğinden bahsetmiştir. Özellikle yarı zamanlı balıkçılıkla uğraşanların, balıkçılık sürelerinde toplam maliyeti değil, yalnızca işletme maliyetlerini dikkate aldıkları ve işletme maliyetlerinin gelir payından daha az olduğu müddetçe de balıkçılıktan vazgeçmeyecekleri bildirilmektedir (Ünal ve Franquesa 2010). Balıkçılıktan elde edilen gelirlerin balığın pazar durumu, avlanma mevsimi, avlanılan balığının bolluğu, ürün kalitesi gibi etkenlerin belirlediği bilinmektedir. Buda balıkçıların bir sonraki balıkçılık sezonunda daha fazla gelir elde etme beklentisini arttırmaktadır. Sonuç olarak Küçük ölçekli balıkçılık yapılması zor ve zahmetli aynı zamanda gelir açısından yetersiz olsa da Çanakkale bölgesi için vazgeçilmez bir uğraş ve geçim kaynağıdır.

\section{Kaynaklar}

Akyol, O., \& Ceyhan, T. (2010). Gökçeada (Ege Denizi) Kıyı Balıkçılığı ve Balıkçılık Kaynakları. Su Ürünleri Dergisi, 27(1), 1-5. http://www.egejfas.org/tr/issue/4998/67653

Akyol, O., \& Perçin, F. (2006). Tekirdağ İli (Marmara Denizi) Kıyı Balıkçılığı ve Sorunlar1. Su Ürünleri Dergisi,23(3), 423426. http://www.egejfas.org/tr/issue/5013/67920

Alıçlı, Z.T., Doğan, K., \& Altunay, M.A. (2019). Marmara Ereğlisi (Tekirdağ) küçük ölçekli balıkçılık faaliyeti ve balıkçıların sosyoekonomik yapısının analizi. Aquatic Research, 2(4), 200-210. https://doi.org/10.3153/AR19019

Ayyıldız, M., \& Balık, İ. 2019. Yalova İli'nde Deniz Balıkçılığı ve Balıkçıların Sosyo-Ekonomik Yap1s1, Kent Akademisi, 12 (38), Issue 2, Pages. 288-298

Benli, K. 2009. İstanbul İli Marmara Denizi Sahil Şeridi Deniz Balıkçılığının Sosyo-Ekonomik Yapısı ve Deniz Ürünleri Pazarlanması. (Yüksek Lisans Tezi). NKÜ Fen Bil. Ens. Tarım Ekonomisi ABD. 186s.

Çalık, S., \& Sağlam, E. N. (2015). Ordu İlinde Küçük Ölçekli Balıkçılığın Sosyo-Ekonomik Yapısının Belirlenmesi. Türk Denizcilik ve Deniz Bilimleri Dergisi, 1(2), 107-113. 
Çeliker, S. A., Korkmaz, A. Ş., Demir, A., Gül, U., Dönmez, D., Özdemir, İ., \& Kalanlar, Ş. (2008). Ege Bölgesi’nde Su Ürünleri Avcılığı Yapan İşletmelerin Sosyo-Ekonomik Analizi. Tarımsal Ekonomi Araştırma Enstitüsü, Ankara, 107s.

Çeliker, S.A., Dönmez, D., Gül, U., Demir, A., Genç, Y., Kalanlar, Ş. \& Özdemir, İ. (2006). Karadeniz Bölgesi'nde Su Ürünler Avcılığı Yapan işletmelerin Sosyo-Ekonomik Analizi, Tarımsal Ekonomi Araştırma Enstitüsü, Yayın No: 143, Ankara.

Demirci, S., Aytekin, N., \& Şimşek, E., (2015). İskenderun Balıkçı Barınağında Sosyo-Ekonomik Durum. SUMDER Su Ürünleri Dergisi Sayı: 5860.

Doğan, K. (2010). İstanbul Su Ürünleri Kooperatifleri ve Ortaklarının Sosyo-Ekonomik Analizi. Journal of FisheriesSciences.com 4(4), 318-328. https://doi.org/10.3153/jfscom.2010035

Doğan, K., \& Gönülal, O. (2011). Gökçeada (Ege Denizi) Balıkçılığı ve Balıkçıların SosyoEkonomik Yapıs1. Karadeniz Fen Bilimleri Dergisi ,2(3),57-69.

FAO (2020). Report of the forty-third session of the General Fisheries Commission for the Mediterranean (GFCM)-Athens, Greece, 4-8 November 2019. GFCM Report no.43.Rome.https://doi.org/10.4060/ca8379en

Franquesa, R., Malouli, I.M. \& Alarcón, J.A. (2001). Feasibility assessment for a database on socioeconomic indicators for Mediterranean fisheries. Studies and Reviews. General Fisheries Commission for the Mediterranean. No. 71. Rome, FAO. 55p. ISBN: 92-5-104643-3

Göncüoğlu, H., Ünal, V., 2011. Fisherwomen in the Turkish fishery, southern Aegean Sea. Journal of Applied Ichthyology, 27:1013-1018.

Göncüoğlu-Bodur, H., Kaykaç, H., Ünal, V., 2017. İzmir Körfezinde Olta ile Kalamar (Loligo vulgaris) Avcılığı Yapan Balıkçıların Sosyoekonomik Analizi. Ege Journal of Fisheries and Aquatic Sciences 34(3): 249-254.

Güngör, G., Özen, S.Ş., \& Güngör, H. 2007. Marmara Denizi Balıkçılığının Sosyo-Ekonomik Yapısı ve Deniz Ürünleri Pazarlaması: Tekirdağ İli Sahil Şeridi Örneği. Tekirdă̆ Ziraat Fakültesi Dergisi, 4 (3): 311-325.

Hoşsucu, H., Erdem, M., Ünal, V., \& Özekinci, U. (1997). Ege Denizi kıyı balıkçılığı yönetimi ve sorunları, KAY'97 I. Ulusal Konferansi, 24-27. https://dergipark.org.tr/tr/pub/kfbd/issue/22231/2 38643
Karadal, E. (2014). Akdeniz Bölgesi (Türkiye) Sahil Şeridi Deniz Balıkçılığının Sosyo-Ekonomik Durumu. (Yüksek Lisans Tezi). Ordu Üniversitesi, Fen Bilimleri Enstitüsü.

Korkmaz, A. Ş. \& Coşkun, T. (2016) Endüstriyel balıkçı teknelerinin sosyo-ekonomik göstergeleri: Sinop ili örneği. Journal of Aquaculture Engineering and Fisheries Research, 2(4): 208216. doi: 10.3153/JAEFR16023

Lery, M. J., Prado, J., \& Tietze, U., (1999): Economic viability of marine capture fisheries. Findings of a global study and an interregional workshop. FAO Rome, Fisheries Tech. Paper, No. 377, 130 $\mathrm{p}$

Özbek, G. (2014). Doğu Karadeniz Bölgesi (Türkiye) sahil şeridi deniz balıkçılığının sosyo-ekonomik durumu (Yüksek Lisans Tezi) Ordu Üniversitesi Fen Bilimleri Enstitüsü, Ordu, Türkiye

Özekinci, U., Cengiz, Ö., \& Bütüner, S.(2006). Çanakkale Bölgesinde Kullanılan Uzatma Ağlarının Donam Özellikleri ve Balıkçıların Sorunlar1. Su Ürünleri Dergisi, 23(3), 481-486.

Özyurt, R. (2013). Orta ve Doğu Karadeniz Bölgeleri'nde Yapılan Küçük Ölçekli/ Artisanal Balıkçılığın Sosyo-Ekonomik Durumu. (Yüksek Lisans Tezi). Fen Bilimleri Enstitüsü, Karadeniz Teknik Üniversitesi.

Sabatella, E., \& Franquesa, R. (2004). Manual of fisheries sampling surveys: methodologies for estimations of socio-economic indicators in the Mediterranean Sea (Vol. 73). Food \& Agriculture Org. ISBN: 92-5-105093-7

Sağlam, N.E., \& Çalık, S. (2016). Giresun ili balıkçılığına genel bir bakış. Ordu Üniversitesi Bilim ve Teknoloji Dergisi, 6(2), 28-37.

Salas, S., Chuenpagdee, R., Seijo, J. C., \& Charles, A., (2007): Challenges in the assessment and management of small-scale fisheries in Latin America and Caribbean. Fish. Res., 87, 5-16

Şahin, S. (2006). Tekirdağ İli Deniz Balikçiliğinin Sosyo- Ekonomik Durumu Ve Pazarlama Yapisi (Yüksek Lisans Tezi) Tekirdağ Ziraat Fakültesi, Tarım Ekonomisi Anabilim Dalı

TUIK (2019). Türkiye İstatistik Kurumu, Haber Bülteni. http://tuik.gov.tr/PreHaberBultenleri.do?id=2766 9; Erişim Tarihi: 24.04.2019

Tzanatos, E., Dimitriou, E., Papaharisis, L., Roussi, A., Somarakis, S., \& Koutsikopoulos, C. (2006). Principal socio-economic characteristics of the Greek small-scale coastal fishermen. Ocean \& Coastal Management, 49(7-8), 511-527. 
Uzmanoğlu, S., \& Soylu, M. (2006). Karasu (Sakarya) Bölgesi Deniz Balıkçılarının SosyoEkonomik Yapısı. Su Ürünleri Dergisi, 23(3), 515-518

Ünal, V. (2001). Foça balıkçılığının sosyo-ekonomik analizi ve sürdürülebilirlik açısından değerlendirilmesi üzerine bir araştırma. (Doktora Tezi). Ege Üniversitesi Fen Bilimleri Enstitüsü, İzmir.

Ünal, V. (2003). Yarı Zamanlı Küçük Ölçekli Balıkçılığın Sosyo-Ekonomik Analizi, Foça (Ege Denizi). E.Ü. Su Ürünleri Dergisi, 20(1-2):165172.

Ünal, V. (2004). Viability of Trawl Fishing Fleet in Foça (the Aegean Sea), Turkey and Some Advices to Central Management Authority. Turkish Journal of Fisheries and Aquatic Sciences, Vol. 4, Issue (2): 93-97.

Ünal, V., \& Franquesa, R. (2010). A comparative study on socio-economic indicators and viability in small-scale fisheries of six districts along the Turkish coast. Journal of Applied Ichthyology, 26(1), 26-34.

Ünal, V., Göncüoğlu, H., Durgun, D., Tunca., S., Güçlüsoy, H., (2015). Viability of small-scale fisheries in Datça-Bozburun Special Environmental Protection Area (SEPA), (Eastern Mediterranean), Turkey. Srour, A., Ferri, N., Bourdenet, D., Fezzardi, D., Nastasi, A., eds. 2015. First Regional Symposium on Sustainable Small-Scale Fisheries in the Mediterranean and Black Sea, 27-30 November 2013, Saint Julian's, Malta. FAO Fisheries and Aquaculture Proceedings No. 39. ISBN 978-92-5-108846-3, 403-415, Rome, Italy.

Ünal, V., \& Ulman, A., (2020). The current state and challenges facing the small-scale fisheries of Turkey. (Edt: Pascual Fernandez, J.J., Pita, C.B., Bavinck, M.) Small-Scale Fisheries in Europe: Status, Resilience, and Governance. MARE Publication Series, ISSN 2212-6260, ISBN 9783-030-37370-2, Springer, $610 \mathrm{p}$.

Ünal, V., Yercan, M., \& Göncüoğlu, H. 2009. Ege Klyılart Su Ürünleri Kooperatifleri, SÜRKOOP$\mathrm{Su}$ Ürünleri Kooperatifleri Merkez Birliği Yayınları, Yayın No:1 ISBN:978-605-60880-0-1, Ankara, $131 \mathrm{~s}$.

Yağlıŏlu, D. (2013). Akçakoca (Batı Karadeniz) balıkçılığı ve balıkçıların sosyo- ekonomik analizi. Ormancllık Dergisi, 9(1), 35-42.
Yazıcıŏlu, Y., \& Erdoğan, S. (2004). SPSS uygulamalı bilimsel araştırma yöntemleri. Detay Yayıncılık, Ankara, (s 53).

Yücel, Ş. (2006). Orta Karadeniz Bölgesi Balıkçılığı ve Balıkçıların Sosyo-Ekonomik Durumu. Su Ürünleri Dergisi, 23(3):529-532.

Zengin, M., \& Güngör, G. (2017). Su Ürünleri Kooperatiflerinin Balıkçılık Yönetimi İçerisindeki Rolu: Marmara Denizi Örneği, Türkiye. Turkish Journal of Aquatic Sciences, 32(2), 102+. 